\title{
Splenic Tuberculosis: A Cause of Pyrexia of Unknown Origin Report of Two Cases
}

\author{
AHMEDUL KABIR, ${ }^{1}$ APARNA DAS, ${ }^{2}$ MAHMUDUL HASSAN BANNA, ${ }^{3}$ BAHARUL MINNAT, ${ }^{4}$ HAM NAZMUL AHASAN, ${ }^{5}$
}

\begin{abstract}
Tuberculosis of spleen is an extremely rare clinical entity. It often poses diagnostic difficulties as microbiological confirmation of diagnosis is not easy. We encountered two casas who presented with prolong fever but no other symptoms. Laboratory data provided no specific information for diagnosis. Abdominal ultrasonography revealed splenomegaly with multiple small hypoechoic lesions within the spleen. A diagnosis of isolated splenic tuberculosis was confirmed after a splenic puncture and histopathological examination.
\end{abstract}

Keywords: TB, Splenic tuberculosis, Splenomegaly

\section{Introduction}

Tuberculosis is perhaps as old as mankind. It is thought to be the oldest of human diseases, however its true incidence and prevalence has never been established. Its causative agent, mycobacteria, is believed to be amongst the oldest bacteria on the earth ${ }^{1}$. In ancient literature, descriptions of various forms of the disease might be found ${ }^{1,2}$. It was believed that with producing effective drugs against it, tuberculosis would not be much more a problem for human health but with its increasing incidence since early 1980's and development of new resistant forms, we recognized our ignorance about all aspects of this disease. These case reports introduce patient with a rare presentation of this "King of diseases". Splenic tuberculosis (splenic TB) is extremely rare and has no characteristic symptoms or abnormal imaging findings. Therefore, it is likely to be misdiagnosed as carcinoma of spleen, splenic abscess or lymphoma. Isolated splenic tuberculosis is rare although secondary involvement in miliary TB is common. The misdiagnosis rate is high if there is no tuberculosis history in other organs. In these case reports, we present the presentation, diagnosis, treatment and a literature review.

1. Associate professor, Dept of Medicine, Dhaka Medical College Hospital

2. Assistant Professor, Dept of Medicine, Dhaka Medical College Hospital

3. Honorary Medical officer, Dept. of Medicine, Dhaka Medical College Hospital

4. Medical Affairs Division, Renata LTD.

5. Professor and Head, Dept of Medicine, Dhaka Medical College Hospital

Correspondence: Dr. Aparna Das, Assistant Professor, Dept of Medicine, Dhaka Medical College Hospital. M; 01914978719

\section{Case Report Case No. 1:}

A 40-year- old women presented with a history of prolong fever for 3 months and weight loss for 10 years. The fever was continuous in nature with an evening peak recorded temperature ranging from $100^{\circ} \mathrm{F}$ to $101^{\circ} \mathrm{F}$. Fever was associated with chills and occasional shivers. There was no history of throat pain, cough, sputum, chest or abdominal pain, night sweats, weight loss or anorexia. Her bladder and bowel habits were normal. Her medical history did not include any TB and HIV infection. She denied any history of recent foreign travel or a family history of TB and AIDS. On admission, when physically examined, her body temperature was $101^{\circ} \mathrm{F}$ and she had mild splenomegaly. Laboratory data showed that her $\mathrm{Hb} \%$ was within normal limits, erythrocytic sedimentation rate (ESR) was $64 \mathrm{~mm}$ in $1^{\text {st }} \mathrm{hr}$, Mantoux Test and HIV antibody reaction were all negative and C-reactive protein level was $69.1 \mathrm{mg} / \mathrm{L}$. Chest $\mathrm{X}$ ray revealed no abnormalities. Abdominal ultrasound scan showed the spleen was enlarged with multiple hypoechoic lesions representing solid foci, one of which was $1.0 \mathrm{~cm} \times 0.8 \mathrm{~cm}$ with a clear boundary.

A USG-guided splenic puncture and biopsy were taken. The histopathological report showed a granuloma nodule with large areas of caseation in the center surrounded by a variable number of Langhan's giant cells and epithelioid cells accompanying inflammatory cells infiltration. Therefore, a final diagnosis of isolated tuberculosis of the spleen was made as there was no other focus of tuberculosis detected in the lung, gastrointestinal tract or lymph nodes. Thus, the patient was started on quadruple anti-TB therapy (Rifampicin, INH, Pyrazinamide and Ethambutol). Seven days later her 
fever and chills subsided. The patient recovered uneventfully.

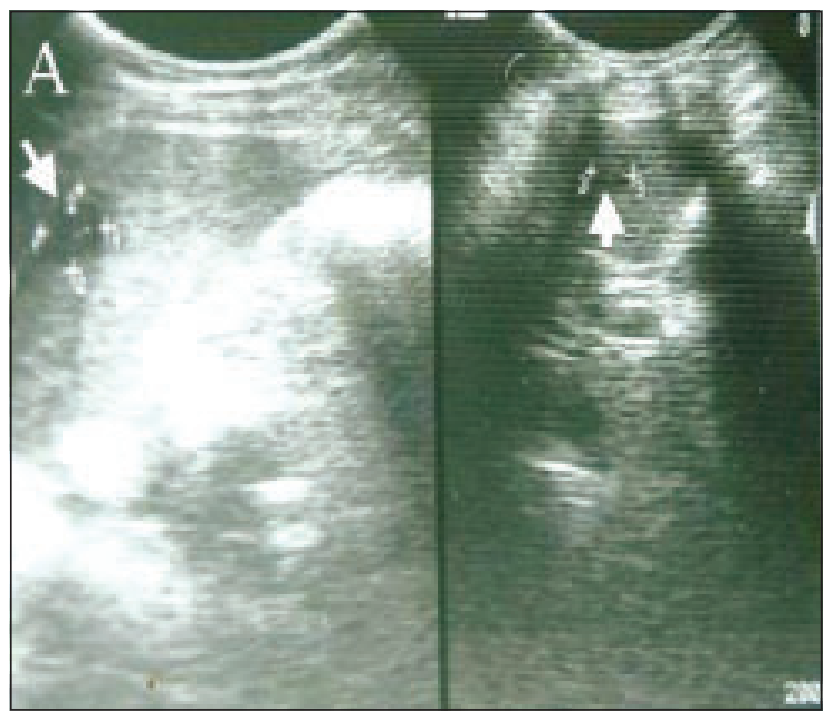

Fig.-1: Ultrasosnogram of multiple hypoechoic shadows in spleen

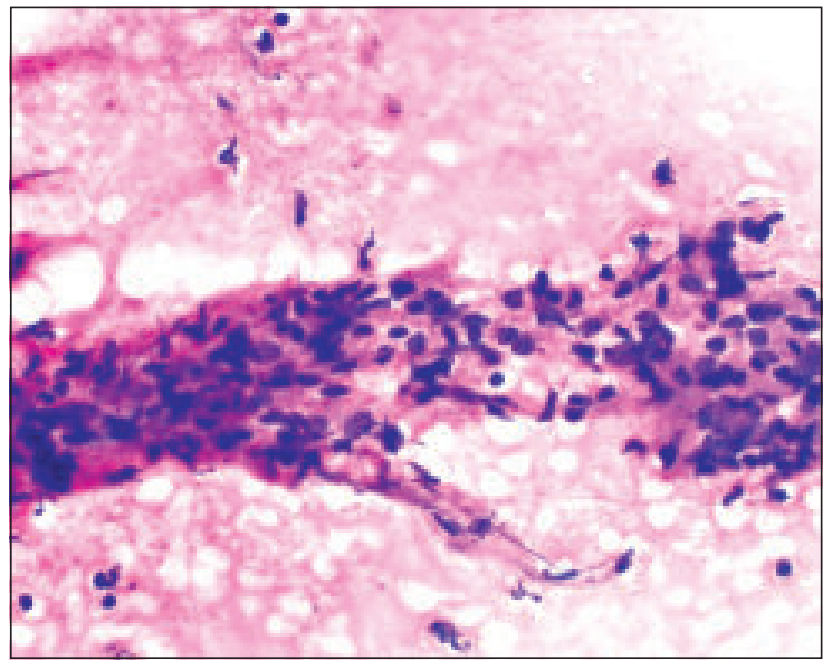

Fig.-2: Epithelioid cells in clusters

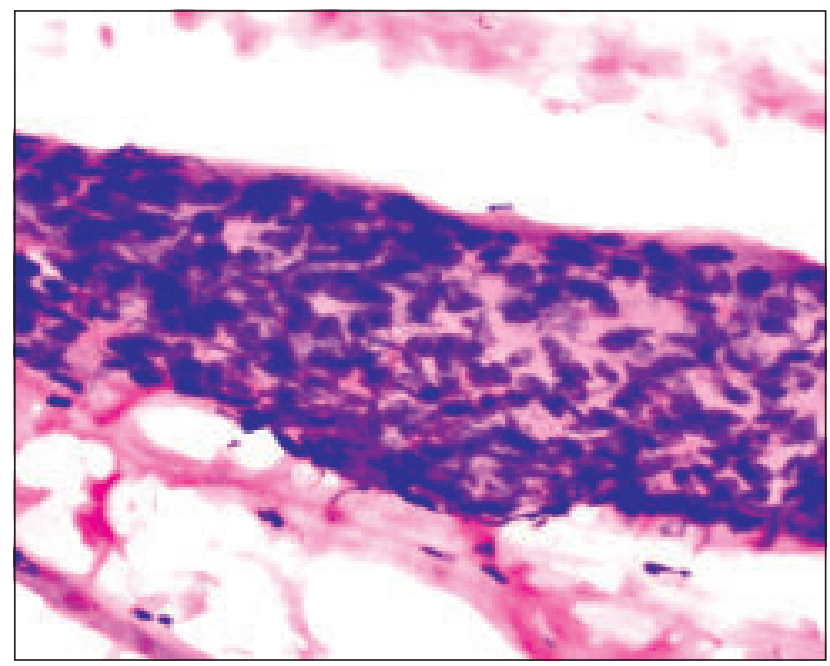

Fig.-3: Epithelioid cells in clusters

\section{Case No. 2}

A 32- year- old women presented with a history of prolong fever, loss of appetite and weight loss for 3 months. On examination, she was moderately anaemic and febrile. Abdominal examination revealed just palpable spleen. Laboratory data showed that her $\mathrm{Hb} \%$ was $10 \mathrm{mg} / \mathrm{dl}$, total count was normal limits, erythrocytic sedimentation rate (ESR) was $120 \mathrm{~mm}$ in $1^{\text {st }} \mathrm{hr}$, Mantoux Test was negative .Chest $\mathrm{X}$ ray revealed no abnormalities. Abdominal ultrasound scan showed the spleen was enlarged with multiple hypoechoic lesions representing spleenic abscess. Histopathology showed caseation necrosis with multiple epitheloid granuloma competeble with tuberculosis.

Table I

Comparison between Clinical features

\begin{tabular}{lcc}
\hline Clinical features & Case No. 1 & Case No. 2 \\
\hline Age & 40 year & 32 year \\
Sex & Female & Female \\
Fever & 3 month & 3 month \\
Anaemia & Absent & Present \\
Spleen & Mildly enlarged & Just palpable \\
\hline
\end{tabular}

Table II

Comparison between investigations

\begin{tabular}{lcc}
\hline Investigations & Case No. 1 & Case No. 2 \\
\hline $\mathrm{Hb} \%$ & $11.8 \mathrm{mg} / \mathrm{dl}$, & $10 \mathrm{mg} / \mathrm{dl}$, \\
ESR & $64 \mathrm{~mm} \mathrm{in} 1^{\mathrm{st}} \mathrm{hr}$ & $120 \mathrm{~mm} \mathrm{in} 1^{\mathrm{st}} \mathrm{hr}$, \\
Chest X-ray & Normal & Normal \\
Mantoux Test & Negative & Negative
\end{tabular}

Abdominal

ultrasound scan

Histopathology spleen was enlarged with multiple hypoechoic lesions representing solid foci, one of which was $1.0 \mathrm{~cm} \times 0.8 \mathrm{~cm}$ with a clear boundary.

Granuloma with large areas of caseation in the center surrounded by a variable number of Langhan's giant cells and epithelioid cells accompanying inflammatory cells infiltration. spleen was enlarged with multiple hypoechoic lesions representing spleenic abscess.

Caseation necrosis with multiple epitheloid granuloma competeble with tuberculosis. 


\section{Discussion}

Tuberculosis is a multi-system disease, $90 \%$ of which locates primarily in lung, whereas isolated splenic tuberculosis, as we present here, is a rare form of extra pulmonary TB. There is a case report of isolated splenic tuberculosis in Bangladesh ${ }^{3}$. Splenic tuberculosis occurs in two forms. The first is its involvement during miliary tuberculosis especially in immunocompromised patients, which is not rare and it's treatment includes classic antituberculous treatment, and if possible improving patient's immunity. Spleen is the third organ becoming involved in miliary T.B. (lung $100 \%$, liver $82 \%$, spleen $75 \%$, lymph nodes $55 \%$, bone marrow $41 \%$ ). ${ }^{4}$ The second form is the primary involvement of spleen which is extremely rare (the same as our patient). In English, French and German literature, from 1965 to 1992, just six cases were reported.$^{5}$ The number of reports of the disease is less than 100 in China according to some expert's estimates. ${ }^{6}$ Patients with AIDS or who are otherwise immunocompetent have been reported to be at a high risk for splenic TB. Although Winternitz (1912) categorized splenic TB as a primary or secondary form, some scholars insist that all patients with splenic TB are secondary to the previous infection of tubercle bacillus in other organs. ${ }^{7}$ In our cases, the patient denied a history of TB and there was no indication of any other involvement in other sites or organs at the time of admission. There are no specific symptoms for establishing the diagnosis of splenic TB. ${ }^{8}$ Fever was the only symptom in both our cases and was one of PUO (pyrexia of unknown origin) as defined by Petersdorf and Beeson in 1961. ${ }^{9}$ Helpful laboratory data includes anemia, elevated ESR, increased CPR and a positive MT test.Ultrasound examination is simple, non-invasive and useful. There are 5 types of pathomorphological classifications for splenic TB including miliary TB, nodular TB, tuberculous spleen abscess, calcific TB and mixed type TB.

CT scan is also helpful in the diagnosis, especially for splenic abscess. However, it has its limitations. On one hand, there are many situations that may have presentations of multiple, hypodense splenic lesions on CT such as malignant lymphoma, metastatic cancer, echinococcal cysts, hemangioma or even infectious diseases due to frequent fever. On the other hand, typical nodules on the splenic capsule are usually too small to be detected easily by CT scan. Fungal splenic abscesses are being increasingly recognized, especially in immunosuppressed patients and Candida is the most involved fungus. However, CT cannot be suggestive of the nature of lesions in spleen. CT guided splenic puncture is becoming a more ideal and popular method nowadays. ${ }^{10}$ Needle biopsy of the spleen is an important method of diagnosis. This can proceed by splenic aspiration puncture under image guidance. The typical manifestation is caseation along with granuloma of epitheloid cells and Langerhan's cells. In other situations, small nodules may be missed on needle biopsy and occasionally laparotomy or even splenectomy may be required. So far, histopathological examination is still the ideal method to confirm the diagnosis. However, many patients are reluctant to accept it due to its invasive nature. Therefore, it is common that patients with the disease are misdiagnosed or diagnosis is delayed.

Like the treatment of pulmonary tuberculosis, treatment of splenic TB must be carried out in accordance with the following principles - timely treatment in combination, regularly and properly through the whole course whether or not an operation is performed. Treatment for tuberculosis should last for more than 6 months. Standard antituberculosis medication should be taken preoperatively and postoperatively if an operation is carried out. Tuberculous splenic abscesses could not be treated with antibiotics alone and early splenectomy which has been suggested by some authors seems is a better approach followed by oral antituberculous drugs. ${ }^{14,15}$

\section{Conclusion}

Despite it's rarity, splenic tuberculosis must be considered in patients' with PUO and splenomegaly, because tuberculosis is endemic in Bangladesh for long time. Even if tuberculosis cannot be confirmed, therapeutic trial of antiTB drugs may be life saving for our people.

\section{Conflict of Interest: None}

\section{References}

1. Evans CC; Historical Background, In: P.D.O Davies,Clinical tuberculosis. Chapman \& Hall, $2^{\text {nd }}$ ed edition,1998; p. 43-51.

2. Asim K. Dult and William W.Stead, Epidemiology and Host factors, In : Schlossberg, Tuberculosis and non tuberculous mycobacterial infections 4 th ed. 1999; p. 654-9.

3. Ahasan HAM N, Karim SR, Ahsan SMM. Tuberculosis of Spleen- An uncommon cause of pyrexia of unknown origin.Bangladesh Journal of Medicine.1999;10:103-104.

4. Nayyar V, Ramakrishna B, Mathew G, et al. Response to antituberculos chemotherapy after splenectomy. J Intern Med. 1993; 233(1): 81-3.

5. Agarwala S, Bhatnagar V, Mitra DK, Gupta AK, et al. Primary tubercular abscess of spleen J Pediatr Surg. 1992; 27(12): 1580-1.

6. Chen XZ, Peng B. (2008). Clinical diagnosis and treatment for splenic tuberculosis. Huaxi Medicine, 23, 114.

7. Singh, B., Ramdial, P. K., Royeppen, E., Moodley, J., \& Chetty, R. (2005). Isolated splenic tuberculosis. Tropical doctor, 35(1), 48-49.

8. Fitzgerald, D. W., Starling, T. R., \& Haas, D. W. Mycobacterium tuberculosis. In G. R. Mandell, J. E. Bennett, \& R. Dolin, Mandell, Douglas, and Bennets Principles and Practice of Infectious Diseases .Philadelphia: Churchill Livingstone Elsevier.2010; 3129-3163.

9. Grange, J. M., \& Zumla, A. I. Tuberculosis. In G. C. Cook, \& A. I. Zumla, Manson's Tropical Diseases .Philadelphia: Saunders Elsevier. 2008; 983-1039.

10. Adil A, Chikhaoui N, Ousehal A, Kadiri R, Splenic tuberculosis . Apropos of 12 cases. Ann Radiol Paris.1995; 38(7-8): 403-7 